DISTRIBUTION STATEMENT A. Approved for public release; distribution is unlimited.

\title{
Portable Multi Hydrophone Array for Field and Laboratory Measurements of Odontocete Acoustic Signals
}

\author{
Paul E. Nachtigall \\ University of Hawaii \\ phone: (808) 247-5297 fax:(808) 247-5831 email: nachtiga@hawaii.edu \\ Award Number: N000141310684 \\ http://www.hawaii.edu/HIMB/
}

\section{LONG-TERM GOALS}

The major goal is to build an array in order to measure the directionality of whistle and clicks produced by odontocetes. Beam patterns and depth profiles of acoustic signals of several species of odontocetes can be collected and analyzed in order to provide better verification of signals collected via passive acoustic monitoring. Additionally, because the array is versatile and portable, other sound sources can be measured and described in various environments.

\section{OBJECTIVES}

This project has several objectives. First, our goal is to build a portable and versatile multi channel array. We have designed a portable 4 to 16 element array that is battery operated and designed to be used both in the field as well as in laboratory settings.

One of the main objectives of this array is to measure the outgoing signals of representative odontocetes so that the identification, direction of travel, depth and location of the animals can be better known for passive acoustic monitoring efforts.

Another main objective is to use this array to improve our knowledge of marine mammal acoustic signal parameters in control settings. Measurements both on a small and large scales will be obtained to look at propagation models of acoustic signals.

An additional objective is to use this array to obtain high resolution measurements of anthropegenic sound sources in the field in order to assess propagation models and levels generated by various activities.

\section{APPROACH}

We are currently building and improving a multi channel array. The current iteration of our array is comprised of up to 16 hydrophones with various cable lengths (up to $60 \mathrm{~m}$ ). Because the array has been designed as independent units, the configuration of the array can be modified to accomodate the research questions of interest, whether it is looking at beam pattern, depth profiles or very finite and detailed measurements close to the sound source. 


\section{Report Documentation Page}

Form Approved

OMB No. 0704-0188

Public reporting burden for the collection of information is estimated to average 1 hour per response, including the time for reviewing instructions, searching existing data sources, gathering and maintaining the data needed, and completing and reviewing the collection of information. Send comments regarding this burden estimate or any other aspect of this collection of information,

including suggestions for reducing this burden, to Washington Headquarters Services, Directorate for Information Operations and Reports, 1215 Jefferson Davis Highway, Suite 1204, Arlington

VA 22202-4302. Respondents should be aware that notwithstanding any other provision of law, no person shall be subject to a penalty for failing to comply with a collection of information if it

does not display a currently valid OMB control number.

1. REPORT DATE

30 SEP 2014

4. TITLE AND SUBTITLE

Portable Multi Hydrophone Array for Field and Laboratory

Measurements of Odontocete Acoustic Signals

6. $\operatorname{AUTHOR}(\mathrm{S})$

7. PERFORMING ORGANIZATION NAME(S) AND ADDRESS(ES)

University of Hawaii,2444 Dole Street,Honolulu,HI,96822

9. SPONSORING/MONITORING AGENCY NAME(S) AND ADDRESS(ES)

12. DISTRIBUTION/AVAILABILITY STATEMENT

Approved for public release; distribution unlimited

13. SUPPLEMENTARY NOTES

14. ABSTRACT

15. SUBJECT TERMS

16. SECURITY CLASSIFICATION OF:

a. REPORT

unclassified b. ABSTRACT

unclassified c. THIS PAGE

unclassified
17. LIMITATION OF ABSTRACT

Same as Report (SAR)
3. DATES COVERED

00-00-2014 to 00-00-2014

5a. CONTRACT NUMBER

5b. GRANT NUMBER

5c. PROGRAM ELEMENT NUMBER

5d. PROJECT NUMBER

5e. TASK NUMBER

5f. WORK UNIT NUMBER

8. PERFORMING ORGANIZATION REPORT NUMBER

10. SPONSOR/MONITOR'S ACRONYM(S)

11. SPONSOR/MONITOR'S REPORT NUMBER(S) 
The analysis programs are also being tested with the current available datasets in order to measure, compare and analyze outgoing clicks and whistles of a bottlenose dolphin and a false killer whale. Our analysis will also be conducted with current passive acoustic monitoring detectors and classifiers in order to assess if the depth and orientation of the animals can generate missed or inaccurate detection and species identification.

Our work can also provide baseline and empirical data for finite element models looking at sound production in odontocetes.

Finally, the array is currently being tested for field measurements of underwater detonations.

\section{WORK COMPLETED}

The array has been tested and all the main components have been assembled. Amplifiers are still being tested and ordered to match the needs of various experimental settings.

Animals have been trained for fixed positioning and click and whistle production. Preliminary beam patterns for both species and for clicks and whistles have been collected with a 24 element array. Elements were $20 \mathrm{~cm}$ apart and measurements were conducted both in the vertical and horizontal planes. Data is currently being analyzed using both custom Matlab routines as well as available PAM detectors and classifiers.

Preliminary measurements of underwater explosive detonations have also been obtained in the field on the Pu uloa Underwater Detonation (UNDET) range during Navy training excercises. The sound generated from an explosive charge equivalent to $17 \mathrm{lbs}$. of TNT was recorded at a range of $1.14 \mathrm{~km}$. Initial analysis shows the magnitude of the sound recorded fits established models for underwater shockwave and acoustic propagation.

\section{RESULTS}

Animals are now fully trained for fixed positioning in a hoop. Click and whistle production has been trained on cue. Current array set up is being tested with laboratory animals for calibration and improvements. Results from the preliminary testing with the 24 element array are still be analyzed and the recordings are being processed through PamGuard and ROCCA.

\section{IMPACT/APPLICATIONS}

These measurement will allow direct comparisons between the types of sounds produced, the way that they change as a function of direction and the difference between species. Directionality in both vertical and horizontal planes may also effect automatic detection and classification during passive acoustic monitoring.

Additionally, this array can be used to measure anthropogenic sounds such as underwater detonation in order to better understand how such sound sources propagate in various environments.

Finally, the results obtained with this array can be used to ground proof models of sound propagation based on anatomical measurements. 
All the results are expected to be published in peer-reviewed journals and provided to the funding agency as they become available.

\section{RELATED PROJECTS}

Preliminary work has been conducted with a different 24 element array in order to obtain horizontal and vertical beam patterns of acoustic signals of a false killer whale and a bottlenose dolphin. The data is currently being analyzed and the different angles and depths are compared for received levels.

Additionally, there are further plans to use the array to record more detonation signatures from underwater explosives training on the Pu uloa UNDET range, and to coorelate those recorded sound levels with behavioral and ecological observations of fish, sea turtle, and coral populations. 